\title{
DIFFERENCES IN VISUAL WORKING MEMORY AMONG STUDENTS
}

\author{
Marie-Lisbet Amundsen, professor \\ Per Einar Garmannslund, professor assistant \\ Buskerud and Vestfold University College \\ Hilde Sofie Stokke, professor assistant \\ Telemark University College, Norway
}

\begin{abstract}
The visual working memory serves as the basis for cognitive processes. Precisely because it forms the basis for cognitive processes in learning, it is of interest to us as teachers to gain greater insight into the possible differences and similarities among students of different specializations. We therefore wanted to see if there are differences between students in the humanities disciplines and students of the science disciplines when it comes to issues of visual working memory. We were based on students at two colleges in Norway, and everyone who participated in the study completed a computer-based test developed by Andreassen at the Department of Psychiatry at Vestfold Hospital (2013). The starting point was the following question: Is it possible to find differences in visual working memory in students of science and humanities disciplines?

We found significant differences. Students in science disciplines score better on visual short-term memory for concrete and abstract. We found also that the spread among the students of humanities disciplines is greater than among students of science studies. There is a need for more studies in order to know if extent learning to use strategies can improve the visual working memory of students who score low on this type of testing.
\end{abstract}

Keywords: Visual working memory, students, humanities disciplines, science disciplines

\section{Introduction}

Visual working memory (VWM) is the short-term memory system that maintains visual representations of stimulus inputs.It serves as a foundation for numerous cognitive processes and tasks, including the ability to locate targets embedded in distractors, to comprehend and reason about visual displays, and to detect changes in visual scenes. (Donkin et 
al.2013:873). Since visual working memory forms the basis of cognitive processes, we believe that it is relevant for teachers to gain further insight into differences and similarities that may exist between the abilities of students from different fields to make use of functional strategies.

Donkin and Shiffrin (2013) note that working memory in the short term is a memory system that maintains visual representations of stimulus inputs, and serves as the basis for a variety of cognitive processes and tasks.According to Hollingworth and Maxcey-Richard (2013:1047), there is a close link between visual working memory and visual attention. They show that visual working memory supports the brief maintenance of multiple visual representations of interference in perceptual input, and that visual attention can be understood as a mechanism that selects one or more sites containing relevant perceptual information of the image.

Using a test for visual working memory, developed (2013) by neuropsychologist, Tor Herman Andreassen, at the Department of Psychiatry at Vestfold Hospital, we wanted to investigate the possibility of detecting differences between Natural Sciences students and Humanities students. We decided to base our study on four groups of students from two Norwegian university colleges. Our aim was to investigate whether we could find differences in visual working memory between sciences students and humanities students.

\section{Method}

The study was conducted at two University Colleges, with a sampling size of 131 participants. The sample consisted of two groups of students: one group consisted of Natural Sciences students $(\mathrm{N}=48)$, and the other humanities students $(\mathrm{N}=83)$. The data was analysed using SPSS.

The participants received information about the test and what we hoped to achieve with the results. The study was based on voluntary, informed participation.All the participants signed an agreement of participation, and were informed that they could withdraw from the tests at any time without stating a reason and without this having any consequences for them.

Participants were presented with a computer screen containing 20 black squares and were told that they would be asked to link the squares in pairs: first images of concrete objects (different coloured socks) followed by abstract shapes. The images were revealed when participants turned the cards. If a pair was found, the cards remained turned.The test was repeated five times, and the images (both concrete and abstract) stayed in the same positions. When the first round had beencompleted, participants were shown the images for eight seconds. 
Having been shown five sets showing concrete objects, participants were shown five sets with abstract shapes.After five minutes, they were again shown two sets with the same concrete images followed by two sets with the same abstract images. The time taken by each participant to complete the tasks was registered automatically, as well as the number of moves needed to complete the task.

The scheduling of the tests was determined by the availability of the computer rooms. The tests were conducted over a period of five days.Virtually all the students in the selectedstudy groups agreed to participate in the tests (91\% positive response).

\section{Presentation and analysis of the findings}

The empirical findings are presented by mean scores forthe variables, standard deviation, mean differences between analysis groups, and the effect size (ES) (Cohen, 1992).

The calculation of ES is based on standard deviation of mean score (M) in the two samples, in the following way:

Effect size $=\left(\right.$ mean $_{\mathrm{B}}-$ mean $\left._{\mathrm{A}}\right) / \mathrm{sum}$ of standard deviations

The calculation of the significance of effect size is shown by Hattie (2009:9) according to the following groupings:

- ES 0.2 implies no effect.

- ES between 0.2 and 0.4 implieslow effect.

- ES $>0.4$ and $<0.6$ implies moderate effect.

- ES $>0.6$ implies high effect.

Hattie (2009) uses these measures of effect size in analysing pupil achievement in schools and states that these ranges should be considered as guidelines that must be interpreted within each specific context and situation.

Mean difference $(M D)$ and effect size are presented such that a positive number points to the first main column (marked "Concretes") and a negative number indicates the second column (marked "Abstracts").

\section{Concrete vs. abstract images}

We wanted to see if there were any differences between the different groups of students in terms of their visual memory abilitywhenrecalling abstract images and concrete images.Participants spent longer on abstract than concrete images $(\mathrm{MD}=17.725)$. This difference was moderately significant with an effect size of 0.705. The mean difference for the number of times the cards were turned is lower (MD $=11.438)$, but when effect size is calculated, the value is high (ES = 1.276), which can be attributed to a wider variance in the student group for the abstract images than the concrete. 
Students seem to spend longer looking at the abstract images than at the concrete images, suggesting that the concrete images are easier to remember than the abstract images.

All:concrete images vs. abstract images

\begin{tabular}{|c|c|c|c|c|c|c|c|c|c|}
\hline \multicolumn{10}{|c|}{ concrete images vs. abstract images } \\
\hline & \multicolumn{2}{|c|}{ concrete images } & & \multicolumn{3}{|c|}{ abstract images } & & & \multirow{3}{*}{$\begin{array}{l}\text { Effect Size } \\
\text { (Cohens d) }\end{array}$} \\
\hline & & & & & & Std. & \multirow[b]{2}{*}{$\begin{array}{c}\text { Mean } \\
\text { difference }\end{array}$} & Pooled & \\
\hline Variables & Mean & $\mathrm{N}$ & $\begin{array}{c}\text { Std. } \\
\text { Deviation }\end{array}$ & Mean & $\mathrm{N}$ & Deviation & & $\begin{array}{c}\text { Std. } \\
\text { Deviation }\end{array}$ & \\
\hline Time & 49,214 & 131 & 19,018 & 65,939 & 131 & 27,642 & $16,725^{\star *}$ & 23,725 & 0,705 \\
\hline Moves & 38,482 & 131 & 10,952 & 49,921 & 131 & 14,199 & $11,438^{\star \star}$ & 8,966 & 1,276 \\
\hline
\end{tabular}

This indicates that abstract images are more difficult to remember than concrete images, thus measuring a different variable.It is not particularly surprising that it is easier to remember concrete images than abstract images.It is easier to connect colours since participants already have created a rule for this connection; they have prior experience of making this type of connection and therefore make a faster connection.The abstract shapes initially appear meaningless for the majority of participants. Here the task depends on creating an effective strategy for coding, making it easier to recallmatches and differences.

Studies on visual working memory indicate that units of memory representations are linked to objects (Vogel, Woodman \& Luck 2001, Gajewski \& Brockmole 2006). Luck and Vogel (1997) discovered that observers are equally good at recalling single objects that vary according to four functions (colour, size, direction and shape), as objects that vary according to a single function only (just colour or direction).

\section{Humanities vs. Natural Sciences - concrete images}

We also wished to discover whether we could find significant differences between Natural Sciences students and Humanities students in terms of visual memory of concrete images.

For concrete images, Humanities students needed longer $(\mathrm{MD}=$ 10.051, ES $=-0.579$ ) than the Natural Sciences students.However, the Humanities students made fewer moves than the Science students.This indicates that science students are better able to recall concrete images than humanities students, whereas the humanities students used fewer moves, indicating that they spent longer looking at each image. 
Concrete images:Humanities students vs. sciences students

\begin{tabular}{|c|c|c|c|c|c|c|c|c|c|}
\hline \multicolumn{10}{|c|}{ concrete images } \\
\hline & \multicolumn{3}{|c|}{ Humanities students } & \multicolumn{3}{|c|}{ Natural Sciences students } & & & \\
\hline Variables & Mean & $\mathrm{N}$ & Std. Deviation & Mean & N & Std. Deviation & $\begin{array}{l}\text { Mean } \\
\text { difference }\end{array}$ & $\begin{array}{l}\text { Pooled } \\
\text { Standard } \\
\text { Deviation }\end{array}$ & $\begin{array}{l}\text { Effect Size } \\
\text { (Cohens d) }\end{array}$ \\
\hline Time & 52,896 & 83 & 21,095 & 42,846 & 48 & 12,596 & $-10,051^{\star \star}$ & 17,373 & $-0,579$ \\
\hline Moves & 36,467 & 83 & 9,309 & 41,967 & 48 & 12,69 & $5,499^{* \star}$ & 7,869 & 0,699 \\
\hline
\end{tabular}

When recalling concrete images, it is probable that the ability to code colours was useful.Connecting colours is a relatively simple task since participants already have developed rules for this; they have prior experience of making this type of connection and therefore understand more quickly what they should look for.Most people initially find the abstract images meaningless; here the challenge is to develop an effective way of coding these images and a strategy for remembering them.

Bradyet al., (2013:791) show that when we perceive a visual scene, we experience an organized and coherent set of objects and surfaces, not the disjointed patches of colour or light that fall on the retina. We also appear to remember coherent, meaningful units.Moments after perceiving a living room, for example, we might remember seeing objects such as a chair, a cup and a picture. In our subjective experience, it may seem that we perceive and remember each object as a coherent and integrated unit. However, a central question at the core of object representation is whether an object is actually represented as a completely bound unit, or whether it is represented with separable properties or dimensions.

\section{Humanities vs. sciences - abstract images}

When we consider the time variable, the Humanities students used significantly longer time ( $\mathrm{MD}=-24.019)$, as also reflected in the high negative effect size (ES $=-1.01)$.

We discovered that the Science students turned the cards more times $(\mathrm{MD}=0.231)$, but the effect size is insignificantly low $(\mathrm{ES}=0.023)$.

There are several possible explanations for this, but we believe the reason to be that with the concrete images, where additional information is available in terms of colour, time is not considered to be as important. This implies that time is a more important factor when remembering visual abstracts. 
Abstract images:Humanities students vs. sciences students

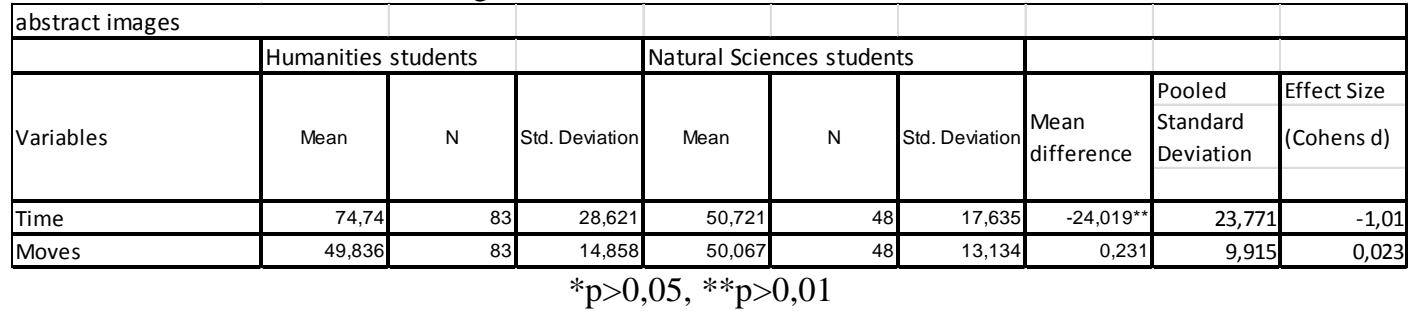

When we consider abstract shapes that are initially perceived as meaningless by most participants, the challenge lies in discovering an effective method for coding, or a functional strategy for remembering the images more easily.Metacognitive learning strategies are not just about the ability to vary learning strategies, but also about finding individual solutions. In this context, this refers to the participants' ability to make associations, with various degreesof creativity, which in turn requires a high level of cognitive activity.

Metcalfe and Kornells (2005) discovered that students put aside parts of their syllabus they consider to be most difficult, in order to first focus on what they believe will be easiest to learn.In other words, students focus first on tasks they see as surmountable, but which require a little effort (zone of proximal development).The learning process thus entails a degree of selection or ranking.

The distinction between cognitive and metacognitive learning strategies may be somewhat unclear.However, Samuelsen (2005) points out that cognitive learning strategies emphasise the cognitive activities associated with the relevant task.These are strategies we use to acquire, organise and expand information in order to create meaning.An example of this would be memorization strategies based on previous knowledge.For example, if the participants had been familiar with Chinese characters, they would have been better skilled at associating the abstract images with words and meanings.

\section{Visual short-term memory vs. visual working memory}

When we compare visual short-term memory with visual working memory, we see a significant difference only for the group as a whole when considering the concrete images $(\mathrm{MD}=2.034)$. This means that participants used less time for the second test than for the first. However, this only gives a weak effect size (ES $=0.155)$. When the group is divided according to what they study, and when we look at the results for abstract images, there is no significant difference. 
Natural Sciences students display better visual memory scores for concrete images than abstract symbols. This may be partially explained by the fact that these participants were more experienced in using computers and computer games and therefore had shorter reaction times than the Humanities students.

Concretes vs. abstracts:short-term memory vs. working memory

\begin{tabular}{|c|c|c|c|c|c|c|c|c|c|c|}
\hline & & short-term m & & & working mer & & & & & \\
\hline & Variables & Mean & $\mathrm{N}$ & Std. Deviation & Mean & $\mathrm{N}$ & Std. Deviation & $\begin{array}{l}\text { Mean } \\
\text { difference }\end{array}$ & rovieu & \begin{tabular}{|l|} 
Effect Size \\
(Cohens d)
\end{tabular} \\
\hline concrete images & Alle & 35,824 & 131 & 13,67 & 33,79 & 131 & 12,617 & $-2,034^{*}$ & 13,154 & $-0,155$ \\
\hline & \begin{tabular}{|l|} 
Humanistisk \\
\end{tabular} & 38,319 & 83 & 14,027 & 36,614 & 83 & 13,616 & $-1,705$ & 13,823 & $-0,123$ \\
\hline & Realfag & 31,51 & 48 & 11,981 & 28,906 & 48 & 8,856 & $-2,604$ & 10,535 & $-0,247$ \\
\hline abstract images & Alle & 47,813 & 131 & 23,791 & 45,531 & 131 & 20,267 & $-2,282$ & 22,099 & $-0,103$ \\
\hline & Humanistisk & 54,554 & 83 & 24,521 & 51,048 & 83 & 21,2 & $-3,506$ & 22,921 & $-0,153$ \\
\hline & \begin{tabular}{|l|} 
Realfag \\
\end{tabular} & \begin{tabular}{l|l|}
36,156 \\
\end{tabular} & 48 & 17,249 & 35,99 & 48 & 14,326 & $-0,167$ & 11,211 & $-0,015$ \\
\hline
\end{tabular}

We see that when the humanities students spent more time, the differences decreased.They looked at the images for a longer period of time; this applied particularly to the abstract symbols.This seems to affect how well they remembered what they saw.Atkinson and Shiffrin (1971) also discovered that slower presentation results in better recall.

In time, the sciences students similarly scored better on remembering concrete images.This means that they remember concrete images better than the Humanities students.The Humanities students needed fewer attempts, but more time.This means that, for concrete images, they too spent longer looking at each image.

It is possible that time may be significant in connection with visual working memory, but we cannot conclude this with any certainty. When it comes to students spending more time on each image, this may be related to them "coding" the information as they look at it.

This may suggest that humanities students develop aless functional learning or recall strategy than science students, but further study is necessary before any such conclusions can be reached.

\section{Summary of findings}

- There are differences related to visual working memory between humanities students and sciences students.

- Sciences students score better on visual working memory for both concrete and abstract images.

- There is a greater spread within the group of humanities students than the sciences students. 
- All the participants spend more time on the abstract tests than the concrete tests.

\section{Method Limitations}

Motivation for learning and interest for the subject matter are important factors in relation to learning and memory.In this study we have eliminated these factors by developing a test we believe to be equally meaningless for all the participants.

Bruner (1960) shows that in an ideal setup, interest for what is being learned is the best motivation for learning.There is every reason to question the participants' motivation for doing their best in the tests in this study.They may have been better motivated if they had been offered the possibility of seeing their own results afterwards.Several of the participants expressed an interest in receiving feedback, but this was not possible.To ensure anonymity, we did not register the participants' names, meaning that we were unable to provide information on individual profiles.

Some of the participants failed to understand that the concrete images and abstract images were placed in the same positions each time the tests were repeated.Those who understood this naturally did better on the tests.

Eisenberger and Cameron (1996) have discovered that external encouragement undermines internal motivation.There is a possibility that the students took part in the tests to assist us, meaning that their inner motivation may not have been optimal.This would reduce the validity of our findings. However, the situation was identical for all participants, and there is no reason to believe that sciences students are more or less motivated to complete the tests than the humanities students.This is reinforced by the fact that there is very little variancein the results from the sciences students.

It may also be possible that the results are affected by psychological factors such as Natural Sciences students being more competitive than humanities students, there being a higher percentage of male participants in the group of sciences students.We could have gained greater insight into this if we had chosen to take gender differences into consideration.However, this was not realistic since the numbers of male humanities students and female sciences students were far too low.The students had already chosen what to study based on their own interests and priorities,so it would be uncertain whether any differences could be attributed to gender or individual differences related to the choice of studies.

\section{Conclusion}

One method of measuring cognitive ability is to look at the ability to recall information in both the short term and long term. This does not only depend on heredity and environment, but also on maturity and on associative 
and strategic thinking skills.Alexander et. al. (1998:130) shows that learning strategies are characterised by being purposeful, willful and effortful, and that the ability to use different strategies is related to a form of metacognitive control.

Whereas metacognition refers to a level of awareness of how one thinks, a metacognitive learning strategy is related more to the effectiveness of cognitive learning strategies.

Metacognitive learning strategies also refer to the ability to switch between using different strategies.Zimmerman (2002) shows that selfregulated learning strategies enable a higher degree of active participation in one's own learning processes.However, De Corte (2003) shows that any form of preparation for future learning should be seen as a form for transference, and that in this context, transference means the degree to which students are able to use functional strategies that may be transferred to concrete learning situations.

Even though visual working memory is affected by individual differences, the picture is more complex than this.Hollingworth and MaxceyRichard (2013: 1056) write that the idea that selective maintenance in VWM is equivalent to sustained visual attention is attractive, but it neglects the flexibility, compexity, and representational diversity of the systems involved.

A greater understanding of how visual working memory may be affected by the time factor would be useful. In order to prepare for learning, greater insight into ways in which students can improve their visual working memory is also highly relevant.Is it possible that greater awareness of the use of strategies may assist in memory processes? If we investigate this topic more closely, it would be preferable to use humanities students since these displayed the greatest variation within the total group.

\section{References:}

Alexander, P. A., Graham, S. and Harris, K.R. (1998) A perspective on strategy research: Progress and prospect. Educational Psychology Review, 10(2):129-153.

Atkinson, R.C. and Shiffrin, R.M. (1971) The control of Short-Term Memory, Scientific American, 224, 82-90.

Brady, T.F., Alvarez, G., Konkle, T. and Olivia, A. (2013) Real-World Objects Are Not Represented as Bound Units: Independent Forgetting of Different Object Details From Visual memory, Journal of Experimental Psychology, Vol.142, Nr.3: 791 - 808.

Bruner, J. (1960) The Process of Education. Cambridge, Mass, Harvard University Press.

Cohen, J. (1992). A Power Primer. Psychological Bulletin, 112(1), 155-159. 
De Corte, E., (2003) Transfer as the productive use of acquired knowledge, skills, and motivations, Current directions in psychological science. 12 (4):142-146.

Donkin, C. et al (2013) Discrete-Slots Models of Visual Working- Memory Response Times, Psychological Review, Vol. 120, Nr. 4: 873-902.

Eisenberger, R. and Cameron,J.(1996) Detrimental effects of reward: Myth or reality? American Psychologists, 51:1153-1166.

Flavell, J.H., Fredrichs, A.G. and Hoyt, J.D. (1970) Developmental changes in memorization processes. Cognitive Psychology, 1:324-340.

Hattie, J. (2009). Visible learning: a synthesis of over 800 meta-analyses relating to achievement. London: Routledge.

Hollingworth, A. and Maxcey-Richard, A. (2013) Selective Maintenance in Visual Working Memory Does Not Require Sustained Visual Attention, Journal of Experimental Psychology: Human Perception and Performance, Vol.39, Nr.4:1047-1058.

Metcalfe, J. and Kornell, N. (2005) A region of proximal learning model of study time and allocation. Journal of Memory and Language, 52 (4):463477.

Zimmerman, B. J. (2002) Becoming a Self-Regulated Learner; An Overview. Theory Into Practice. 